\title{
Medication reconciliation and review for older emergency patients requires improvement in Finland
}

\author{
Lotta Schepel $^{\mathrm{a}, \mathrm{b}, *}$, Lasse Lehtonen $^{\mathrm{c}}$, Marja Airaksinen ${ }^{\mathrm{b}, \mathrm{d}}$, Raimo Ojala ${ }^{\mathrm{e}}$, Jouni Ahonen ${ }^{\mathrm{e}}$ \\ and Outi Lapatto-Reiniluoto ${ }^{\mathrm{c}}$ \\ ${ }^{a}$ HUS Pharmacy, Hospital Pharmacy of Helsinki University Hospital (HUS), Finland \\ ${ }^{\mathrm{b}}$ Specialization Programme of Hospital and Health Centre Pharmacy, Clinical Pharmacy Group, \\ Faculty of Pharmacy, University of Helsinki, Finland \\ ${ }^{\mathrm{c}}$ Helsinki University Hospital and University of Helsinki, Finland \\ ${ }^{\mathrm{d}}$ Clinical Pharmacy Group, Faculty of Pharmacy, University of Helsinki, Finland \\ ${ }^{\mathrm{e}}$ KUH Pharmacy, Hospital Pharmacy of Kuopio University Hospital, Finland
}

\begin{abstract}
.
BACKGROUND: $10-30 \%$ of hospital stays by older patients are drug-related. The admission phase is important for identifying drug-related problems, but taking an incorrect medication history often leads to medication errors.

OBJECTIVES: To enhance medication history recording and identify drug-related problems (DRPs) of older patients admitted to emergency departments (EDs).

METHODS: DRPs were identified by pharmacists-led medication reconciliation and review procedures in two EDs in Finland; Helsinki University Hospital (HUS), and Kuopio University Hospital (KUH). One-hundred-and-fifty patients aged $\geq 65$-years, living at home and using $\geq 6$ medicines were studied.

RESULTS: $100 \%$ of patients $(\mathrm{N}=75)$ in HUS and $99 \%$ in $\mathrm{KUH}(\mathrm{N}=75)$, had discrepancies in their admission-medication chart recorded by the nurse or physician. Associations between admission-diagnosis and drug-related problems were found in 12 patients (16\%) in HUS and 22 patients $(29 \%)$ in KUH. Of these, high-alert medications (e.g. antithrombotics, cytostatics, opioids) were linked to eight patients (11\%) in HUS and six patients (8\%) in KUH. Other acute DRPs were identified in 19 patients $(25 \%)$ in HUS and 54 patients (72\%) in KUH. Furthermore, 67 patients (89\%) in HUS and all patients in KUH had non-acute DRPs.
\end{abstract}

CONCLUSIONS: Medication reconciliation and review at admission of older ED patients requires improvement in Finland.

Keywords: Emergency department, medication reconciliation, medication review, drug-related problems, older patients, clinical pharmacy, high-alert medications, polypharmacy

\section{Introduction}

The majority of hospitalised patients are admitted via the emergency departments (EDs). The hectic environment with short patient admission processing times, large patient volumes and growing numbers of complicated and chronically ill patients without accurate medical history, make ED a critical point from the medication safety perspective. Medication errors are common at the admission stage [1]. Estimated medication error rates vary from $4 \%$ to $14 \%$ [2, 3]. Even one third of prescribing errors that occur in hospitals are a consequence of an incorrect medication history taken at the time of admission

\footnotetext{
${ }^{*}$ Address for correspondence: Lotta Linnea Schepel, Stenbäckinkatu 9, FI-00029 HUS, Helsinki, Finland. Tel.: +358 (0) 50438 6748; E-mail: lotta.schepel@hus.fi.
} 
[4]. Thus, medication reconciliation should also be carried out at the admission of ED patients. It is one of the key strategies to prevent adverse drug events and improve patient safety at all transitions in care $[5,6]$. A clinical pharmacist seems to obtain more comprehensive medication histories than physicians [6].

Older ED patients ( $\geq 65$ years) experience medication errors more often than do younger ED patients because of complex medications and polypharmacy [7]. Age-related physiological, pharmacokinetic and pharmacodynamic changes make older patients more vulnerable to the effects of the drugs [8]. In addition, there are medications that pose a high risk for harmful effects and medication errors. These high-risk or high-alert medications include medications with a narrow therapeutic index (NTI) [9-11]. Incident rates with these medications may not necessarily be higher than with other medications, but when incidents do occur their impact on the patients are potentially more harmful $[10,11]$.

It is recommended that regular medication reviews are performed in order to manage polypharmacy by identifying, resolving and preventing drug-related problems [12]. Different medication review procedures are internationally used in both outpatient and inpatient settings [13-15]. A previous study found that a pharmacist-led medication review for older ED patients with polypharmacy reduced hospital admissions [16]. Older emergency patients are recommended to be systematically screened for clinically relevant drug-related problems [17]. In the present study, the prospective screening procedure for older ED patients was combined with the recording of medication history and with the medication reconciliation and review. The recording of the medication history and medication reconciliation and review were performed by clinical pharmacists in two EDs, which were compared and evaluated. The aim of this study was, therefore, to demonstrate the need for enhancing the recording of medication history at admission of elderly ED patients in Finland. The taking of medication history, medication reconciliation and review had not been routine procedures at ED admission in Finland until this study.

\section{Methods}

\subsection{Setting}

The study was conducted from April 2014 to January 2015 in the respective emergency department of two Finnish university hospitals. Two different EDs were chosen for comparing the feasibility of the pharmacist-led medication reconciliation and medications review process in both settings. 1) Helsinki University Hospital (HUS) provides specialized tertiary medical care, whereby 3000 hospital beds serve a regional population of 1.6 million in the capital metropolitan area of Finland. The ED in HUS has approximately 80 patient visits per day with internal, surgical and neurological specialities for patients older than 16 years of age. Clinical pharmacy services are provided in the EDs, but the taking of medication history including medication reconciliation and review have not been provided. 2) Kuopio University Hospital (KUH) provides specialised medical care with 730 beds that serve over 840,000 residents in Eastern Finland. The ED of KUH usually has 200 patient visits per day and provides tertiary, secondary and acute primary care. A clinical pharmacist the KUH-ED has been recording medication history including medication reconciliations and reviews on a weekly basis since 2013 .

\subsection{Participants}

The study was targeted at older ED patients with polypharmacy. The inclusion criteria were the following: 1) $\geq 65$ years old; 2) Finnish speaking; 3) home-dwelling; 4) oriented to time and place or having a caring close relative who could be interviewed instead and 5) using $\geq 6$ medications (including over-the-counter medications, dietary supplements and herbal products) according to the admission medication chart recorded by either the nurse or the physician in the ED. Two clinical pharmacists (one 
in HUS and the other in KUH), both of whom were accredited for conducting medication reviews, worked from Monday to Friday 8am-6pm. They chose the first one or two patients who met the inclusion criteria per day. All study participants (including caring close relatives who were interviewed) gave their written informed consent before participation in the study.

\subsection{Procedure for medication history recording including medication reconciliation and review}

The prospective procedure applied in this study was designed not to interfere with normal ED routines or passing-times. The starting point of the pharmacists-led medication reconciliation was the admission medication chart taken by a nurse or a physician. In addition, clinical pharmacists checked the possible referral medication chart and medication charts from previous hospital stays. The information gathered from these charts were used to start the bed-side patient interview conducted at ED. In some cases relatives or other care givers were also interviewed. The structured interview form (see Additional File 1) was based on the clinical interview guide used in the Finnish Comprehensive Medication Review procedure [18]. The content of DRP risk assessment tool, which is targeted at nurses for the identification of the clinically most significant DRPs in older adults, was also reviewed for content validation [19]. Medication reviews were conducted by the clinical pharmacists after medication reconciliation. The pharmacists used a medication review form (see Additional File 2), which had been modified from Comprehensive Medication Review procedure to be appropriate for the emergency setting [18]. Pharmacists had full access to patients' clinical and medical data, including laboratory results (Type III clinical medication review according to Clyne's typology) [20]. Special attention was also paid to problems related to high-alert medications $[10,11]$ in order to identify the ED's high-alert medications at the admission stage.

\subsection{Classification of drug-related problems in the mediation review procedure}

The classification of the drug-related problems was done according to the medication review form (see Additional File 2). The identified drug-related problems were divided in three groups as follows:

1) Drug-related problems linked to admission diagnoses. The root-cause relationship was judged by comparing the patients' symptoms and signs at admission (e.g. bleeding, constipation, dizziness) to the established adverse drug reactions of used medications with possible impacts of clinically problematic interactions and renal insufficiency.

2) The severe drug-related problems that were not related to admission diagnoses, but needed immediate changes at ED (dose adjustment with renal insufficiency, adverse drug reactions) that were categorised as acute.

3) The less severe drug-related problems (e.g. re-considering the need or efficacy of the medication, need for monitoring) that could be resolved later after discharge and were determined to be nonacute.

Before reporting the findings to the ED physicians, all reported cases were approved by the study supervising physicians and they were considered to be clinically relevant. All clinically relevant findings were reported to the ED physicians orally and were documented in the patient information system.

\subsection{Data analyses}

The used procedure in both EDs were assessed by the number of discrepancies and drug-related problems that were identified by the clinical pharmacists. The data were analysed by using descriptive statistics. We calculated 1) patients characteristics; 2) number and frequencies of discrepancies in 
admission medication charts that had been recorded for each patient by nurses or physicians and which was subsequently compared with medication reconciliation procedure conducted by pharmacists; 3 ) number and frequencies of clinically problematic drug-related problems (admission related, acute and non-acute) and their subtypes according to the medication review form. The results from HUS and KUH were analysed separately to find any possible differences in the feasibility of the procedure performed in the ED of either a tertiary or secondary hospital.

\section{Results}

\subsection{Patient characteristics}

A total of 150 ED patients ( 75 of HUS and 75 of KUH) were included. The patient characteristics are presented in Table 1. The patients in KUH were slightly older and used more medications than those in HUS.

\subsection{Accuracy of the medication charts}

Every patient in HUS $(n=75)$ and all but one patient in KUH $99 \%(n=74)$ had discrepancies in the medication history as taken by the ED nurse or physician when compared to the pharmacists reconciled medication chart. Nearly four-fifths, $79 \%$ of patients in HUS and $65 \%$ of patients in KUH had at least one omission of long-term medication and the majorities of these (63\% in HUS and $47 \%$ in KUH) were related to prescription medications. Omissions of PRN (pro re nata, used as needed) medications were even more common: $92 \%$ of patients in HUS and $91 \%$ of patients in KUH had these and they were typically related to over-the-counter medications (72\% in HUS and KUH). In HUS 33\% and in KUH $48 \%$ of patients had additional medications in the admission medication chart obtained by normal process, which were not really in use.

Table 1

Patient characteristics $(\mathrm{N}=150)$

\begin{tabular}{lcc}
\hline & HUS $(n=75)$ & KUH $(n=75)$ \\
\hline $\begin{array}{l}\text { Age, years (range) } \\
\text { mean (range) }\end{array}$ & $76(65-92)$ & $79(66-98)$ \\
$\begin{array}{l}\text { Sex, n (\%) } \\
\text { female }\end{array}$ & $46(61 \%)$ & $42(56 \%)$ \\
male & $29(39 \%)$ & $33(44 \%)$ \\
Specialty, n (\%) & & \\
surgery & $30(40 \%)$ & \\
$\quad$ internal medicine & $27(36 \%)$ & $\mathrm{NA}$ \\
neurology & $13(17 \%)$ & \\
pulmonary & $5(7 \%)$ & \\
Number of used medications, n (range) & & $17(8-27)$ \\
all medications & $15(6-23)$ & $11(6-23)$ \\
long-term medications & $9(4-20)$ & $5(1-14)$ \\
PRN medications** & $4(0-11)$ & $1(0-4)$ \\
medications prescribed in the ED & $2(0-8)$ & \\
\hline
\end{tabular}

*secondary/primary care ED: patients are arriving without a referral and meet general physician first; ${ }^{* *}$ pro re nata $=$ as needed. 
Table 2

Clinically harmful drug-related problems (DRPs, HUS: $n=316$; KUH: $n=446$ ) obtained from medication reviews of 150 patients

\begin{tabular}{|c|c|c|c|c|c|c|}
\hline \multirow[b]{2}{*}{ Findings } & \multicolumn{3}{|c|}{ HUS } & \multicolumn{3}{|c|}{ KUH } \\
\hline & $\overline{\text { Patients }(n=75)}$ & DRPs $(n=316)$ & DRPs/patients & Patients $(n=75)$ & DRPs $(n=446)$ & $\overline{\text { DRPs/patients }}$ \\
\hline $\begin{array}{l}\text { Drug-related } \\
\text { problems certainly } \\
\text { or probably related } \\
\text { to admissions }\end{array}$ & $n=12(16 \%)$ & $n=30(9 \%)$ & 2.5 & $n=22(29 \%)$ & $n=43(9 \%)$ & 2.0 \\
\hline $\begin{array}{l}\text { Acute drug-related } \\
\text { problems }\end{array}$ & $n=19(25 \%)$ & $n=50(16 \%)$ & 2.6 & $n=54(72 \%)$ & $n=111(25 \%)$ & 2.1 \\
\hline $\begin{array}{l}\text { Drug-related, } \\
\text { non-acute problems }\end{array}$ & $n=67(89 \%)$ & $n=236(75 \%)$ & 3.5 & $n=75(100 \%)$ & $n=293(66 \%)$ & 3.9 \\
\hline $\begin{array}{l}\text { No drug-related } \\
\text { problems }\end{array}$ & $n=6(8 \%)$ & & & $n=0(0 \%)$ & & \\
\hline
\end{tabular}

\subsection{Drug-related problems associated to admission diagnoses}

As many as $92 \%(n=69 / 75)$ of patients in HUS and $100 \%$ of patients in KUH had clinically relevant drug-related problems (Table 2). Drug-related problems were associated to admission diagnoses of 12 patients (16\%) in HUS and 22 patients (29\%) in KUH (Table 3). There were 30 (2.5 per patient) patients in HUS and 43 (2.0 per patient) in KUH for drug-related problems associated to admission diagnoses and the majority of these were adverse drug reactions or clinically problematic interactions (Figs. 1 and 2).

The US Institute for Safe Medication Practices (ISMP) has a list of high-alert medications [10, 11] some of which contributed to the admission of eight patients (11\%) in HUS and six patients (8\%) in KUH (Table 3). These medications included antithrombotics, opioids, oral hypoglycaemic agents and cytostatics. Antithrombotics were related to bleedings in seven patients. Cytostatics were related to infections and fever for two patients. Empirically established adverse drug reactions of opioids such as constipation and bile duct spasm were related to admission diagnoses of four patients. Ineffective medications (ineffective treatment or dose) were related to two admissions and this was linked to ineffective opioids and oral hypoglycaemic agents. In addition to the high-alert medications, other medications were related to diagnoses of four patients (5\%) in the HUS group and 15 patients (10\%) in the KUH group (Table 4). Antihypertensives and diuretics were usually related to a weakened general condition, dizziness, collapses and falls. Anticholinergic agents and benzodiazepines were related to falls, whereas antibiotics were related to diarrhoea.

\subsection{Other acute drug-related problems requiring action in the ED}

There were 19 patients (25\%) in HUS that presented with 50 acute drug-related problems (2.6 per patient, Table 2) that required action in the ED. The majority of these problems were related to the taking of an inappropriate dose or medication by a patient with renal insufficiency (32\%) followed by clinically problematic interactions (16\%), re-considering the need or efficacy of the medications (12\%) and adverse drug reactions (10\%, Fig. 1). A typical patient in the HUS group had renal insufficiency with several inappropriate medications or doses (NSAIDs, ACE-inhibitors, statins, ASA, codeine, cefuroxime, metformin, digoxin, methotrexate or radio contrast media). Other common suggestions that were made were recommendations for using proton pump inhibitors and paracetamol instead of 
Table 3

Admission diagnoses (HUS: $n=8$, KUH: $n=6$ ) associated with high-alert medications [10, 11]*

\begin{tabular}{|c|c|c|c|}
\hline Unit & Admission diagnoses & Medications & $\begin{array}{l}\text { High-Alert Medication } \\
\text { Group }\end{array}$ \\
\hline HUS & dyspnoea, anaemia & $\begin{array}{l}\text { rivaroxaban* }+ \\
\text { fluvoxamine }\end{array}$ & Antithrombotics \\
\hline HUS & anaemia, melena & warfarin* + ASA $^{*}$ & Antithrombotics \\
\hline HUS & haematuria & $\begin{array}{l}\text { enoxaparin (+ renal } \\
\text { insufficiency) }\end{array}$ & Antithrombotics \\
\hline HUS & $\begin{array}{l}\text { retroperitoneal } \\
\text { haemorrhage }\end{array}$ & $\begin{array}{l}\text { warfarin* }(+ \\
\text { amitriptyline), } \\
\text { methotrexate* }^{*} \text { citalopram } \\
(+ \text { omeprazole), } \\
\text { metylprednisolon, } \\
\text { paracetamol }\end{array}$ & $\begin{array}{l}\text { Antithrombotics, } \\
\text { Cytostatics }\end{array}$ \\
\hline HUS & infection, fever seizure & hydroxyurea* & Cytostatics \\
\hline HUS & stomach pain, constipation & $\begin{array}{l}\text { tramadol* }+ \text { codeine }^{*}+ \\
\text { doxepin }+ \\
\text { hydrochlorothiazide }+ \\
\text { bisoprolol }\end{array}$ & Opioids \\
\hline HUS & bile duct spasms & paracetamol + codeine* & Opioids \\
\hline HUS & $\begin{array}{l}\text { ulcers in left-foot toes, f-P } \\
\text { glucose } 11\end{array}$ & $\begin{array}{l}\text { metformin* }+ \\
\text { pioglitazone* (ineffective) }\end{array}$ & $\begin{array}{l}\text { Oral hypoglycaemic } \\
\text { agents }\end{array}$ \\
\hline KUH & melena & $\begin{array}{l}\mathrm{ASA}+\text { low dose ASA + } \\
\text { meloxicam + ibuprofen }\end{array}$ & Antithrombotics \\
\hline KUH & $\begin{array}{l}\text { weakened general } \\
\text { condition, anaemia }\end{array}$ & $\begin{array}{l}\text { warfarin }{ }^{*}+\mathrm{ASA}^{*}+ \\
\text { tramadol }^{*}+\text { methotrexate* } \\
+ \text { prednisolon }^{*}\end{array}$ & $\begin{array}{l}\text { Antithrombotics, } \\
\text { Cytostatics, Opioids }\end{array}$ \\
\hline KUH & $\begin{array}{l}\text { stomach pain, } \\
\text { haematemesis, melena }\end{array}$ & $\begin{array}{l}\mathrm{ASA}^{*}+\text { sitalopram }+ \\
\text { tramadol }{ }^{*}+\text { metamizole }\end{array}$ & Antithrombotics, Opioids \\
\hline KUH & fever & hydroxyurea* & Cytostatics \\
\hline KUH & leg pain worsening & $\begin{array}{l}\text { paracetamol + codeine* } \\
\text { (ineffective) }\end{array}$ & Opioids \\
\hline KUH & intestinal obstruction & $\begin{array}{l}\text { paracetamol }+ \text { codeine }{ }^{*}+ \\
\text { atenolol }+ \text { atorvastatin }\end{array}$ & Opioids \\
\hline
\end{tabular}

ASA = acetylsalicylic acid.

ibuprofen for analgesia to patients at risk of bleeding. There were 54 patients (72\%) in KUH group whom had presented with 111 acute drug-related problems (2.1 per patient, Table 2), which were usually related to adverse drug reactions (24\%), clinically problematic interactions (15\%), change of administration schedule or route (15\%) or starting new medications (11\%, Fig. 2). Typical acute findings in $\mathrm{KUH}$ were related to adverse drug reactions which were treated with new medications.

\subsection{Drug-related, non-acute problems}

Two-thirds of patients 67 (89\%) in HUS had drug-related, non-acute problems that needed action after discharge (Table 2). There were 236 drug-related problems (3.5 per patient), which were predominantly related to the re-consideration of the need or efficacy of the currently used medication 


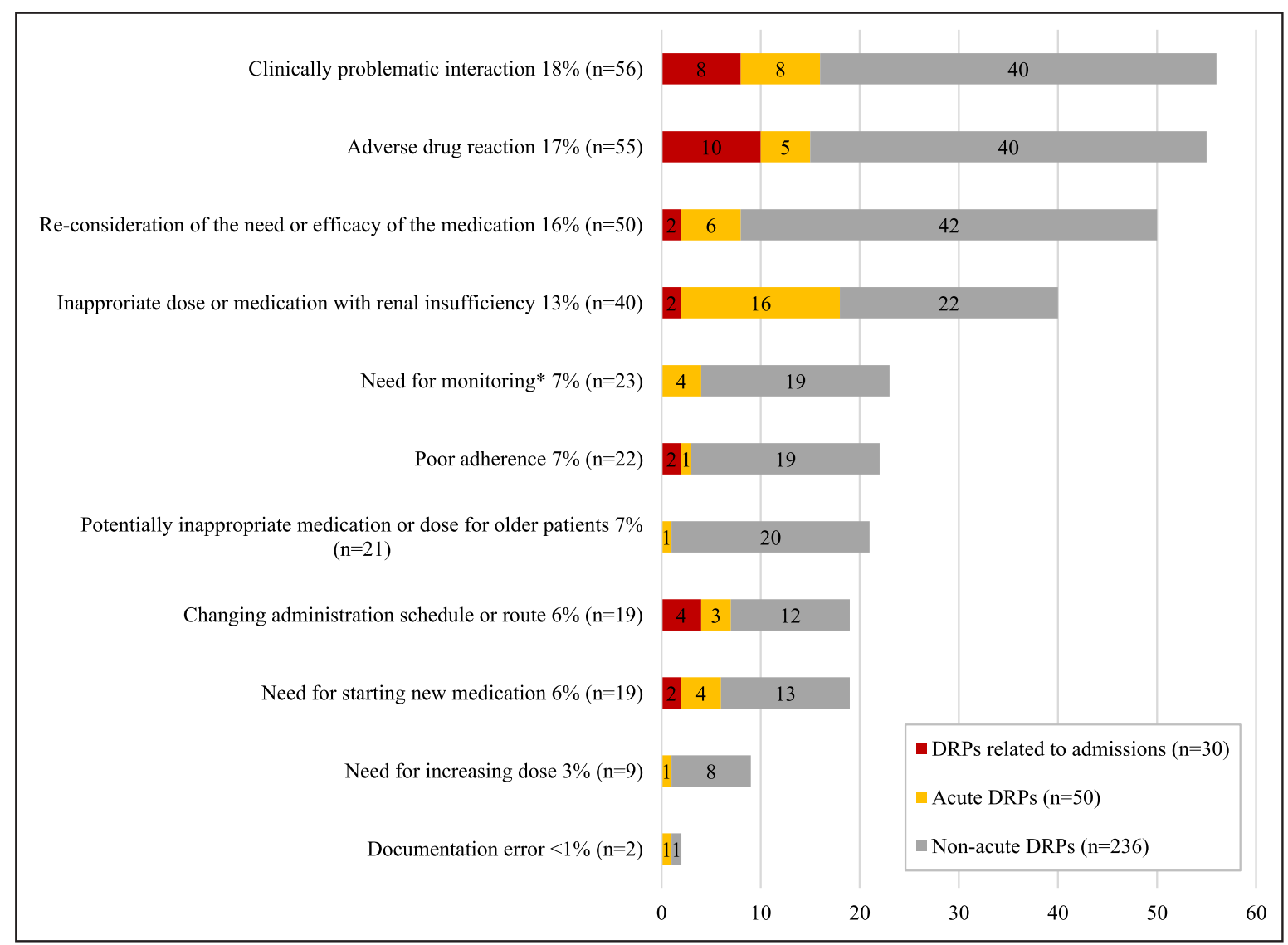

Fig. 1. The clinically relevant drug-related problems (DRPs, $n=316$ ) obtained from 75 medication reviews in HUS. *Monitoring: therapeutic drug monitoring $(n=9)$, checking laboratory results $(n=7)$, bone mass measurement $(n=4)$, mini-mental state examination $(n=3)$.

(18\%), adverse drug reactions (17\%), clinically problematic interactions (17\%), renal insufficiency $(9 \%)$ and potentially inappropriate medication or dose for the elderly (9\%, Fig. 1). Every patient in the KUH group had drug-related, non-acute problems (Table 2). There were 293 non-acute DRPs (3.9 per patient), which were typically related to reconsidering the need or efficacy of the medication (23\%), adverse drug reactions (15\%) and monitoring (14\%, Fig. 2).

\section{Discussion}

The accurate medication history recording and the medication chart is the basis for safe pharmacotherapy and a starting point for medication reviews. We found that the current process of medication reconciliation at the admission of older ED patients in Finland is not adequate. Indeed, there was only one patient of the KUH group whose admission medication chart was accurate and none of the HUS group's medication were accurate. Incorrect medication history recorded at admission leads to prescription errors [4] and may complicate the identification of the correct admission diagnosis [21]. In general, adequate resources (time and staff) are not allocated for the recording of the medication history process, which includes medication reconciliation and review. Moreover, responsibilities between health care professionals have not been explicitly demarked or agreed upon. Clinical pharmacists are not widely assigned for recording medication history and the medication reconciliation processes in 


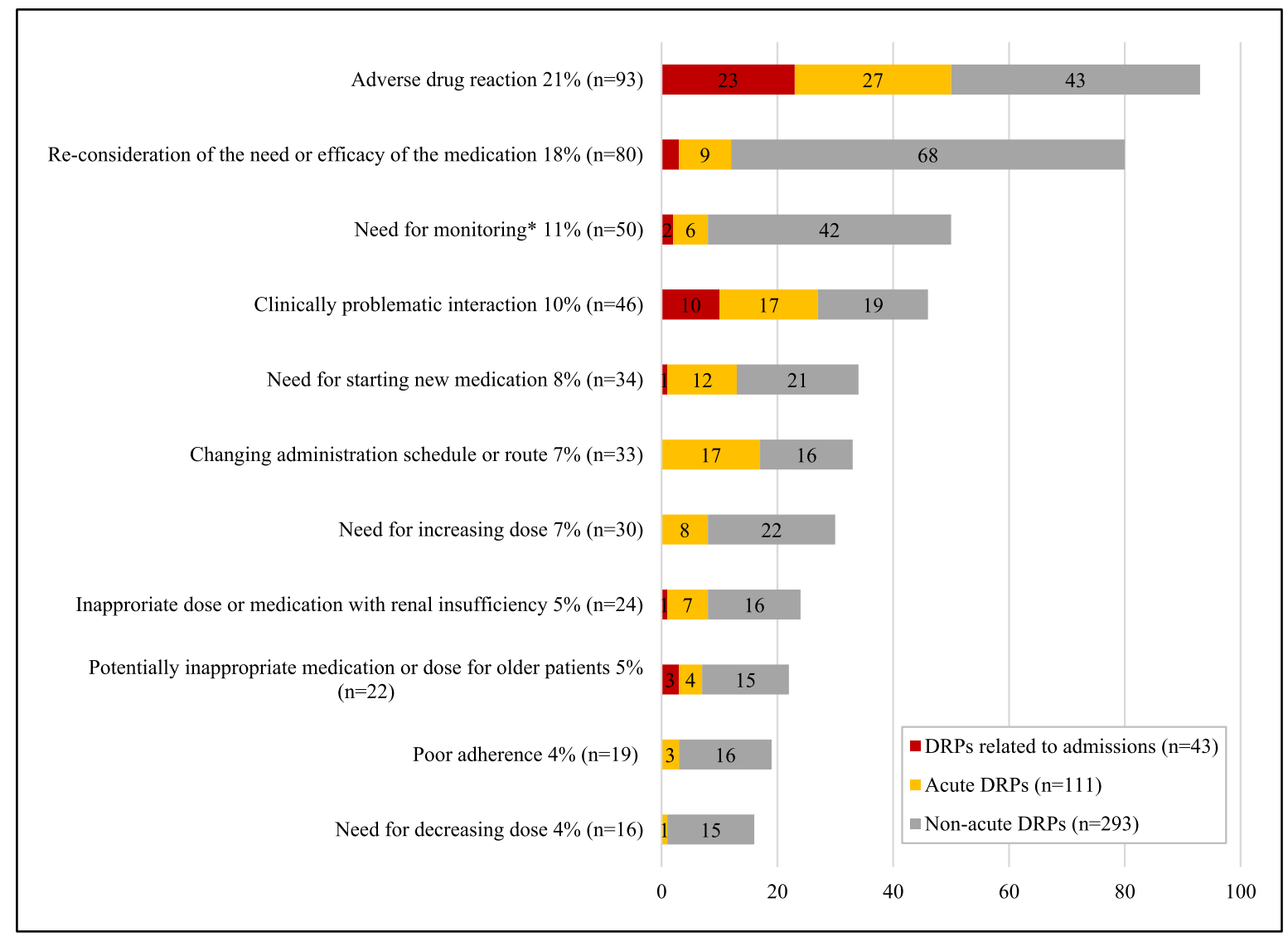

Fig. 2. The clinically relevant drug-related problems (DRPs, $n=447$ ) obtained from 75 medication reviews in KUH. *Monitoring: checking laboratory results $(n=35)$, orthostatic measurement $(n=9)$, bone mass measurement $(n=4)$, therapeutic drug monitoring $(n=2)$.

Finland even though there is evidence on benefits of their involvement from other countries with more advanced clinical pharmacy practices $[6,22]$.

Our study showed that it is possible to prospectively identify and solve clinically relevant drugrelated problems of elderly ED patients with a pharmacists-led medication review. The used medication review procedure is applicable to acute care settings, because it does not impede or slow down the ED admission or the processing times. We have no exact data of the time spent per patient in the ED admission process, but the process was designed not to prolong the treatment time of the patients. The medication reconciliation process took approximately 10-30 minutes per patient, whereas medication reviews usually take 1-2 hours per patient. It should be noted that using the knowledge of clinical pharmacists at this level will save time in the long-run because it allows more time for the nurses and physicians to concentrate on treating the patient. Earlier studies have shown that $10-30 \%$ of hospital stays for older patients are drug-related [23, 24]. In the present study $16 \%$ of HUS patients and $29 \%$ of KUH patients had drug-related problems that were certainly or probably linked to admissions (Table 2). In addition, acute drug-related problems that required actions at ED were identified for $19 \%$ of HUS patients and $72 \%$ of KUH patients. As much as $89 \%$ in HUS and every patient in KUH had drug-related, non-acute problems, which should be resolved later after ED discharge. This reveals that medications reviews should also be conducted on older patients with polypharmacy in non-acute settings. 
Table 4

Other than high-alert medications associated with admission diagnoses (HUS: $n=4$, KUH: $n=15$ )

\begin{tabular}{|c|c|c|c|}
\hline Unit & Admission diagnoses & Medications & Medication Group \\
\hline HUS & fever, diarrhoea & $\begin{array}{l}\text { lymecycline }+ \text { calcium }+ \\
\text { magnesium }\end{array}$ & Antibiotics, Minerals \\
\hline HUS & stomach pain, high CRP & $\begin{array}{l}\text { etoricoxib + low dose ASA (no } \\
\text { proton pump inhibitors) }\end{array}$ & Antithrombotics, NSAIDS \\
\hline HUS & headache, dizziness, nausea & $\begin{array}{l}\text { dipyridamole }+ \text { bisoprolol }+ \\
\text { valsartan }+ \text { moksonidine } \\
\text { furosemide (ortostatism, } \\
\text { temporal relationship) }\end{array}$ & $\begin{array}{l}\text { Antithrombotics, } \\
\text { Antihypertensives, Diuretics }\end{array}$ \\
\hline HUS & dizziness, nausea & $\begin{array}{l}\text { bisoprolol (patient experience, } \\
\text { temporal relationship) }\end{array}$ & Antihypertensives \\
\hline KUH & diarrhoea & several antibiotic regimens & Antibiotics \\
\hline KUH & atrial fibrillation & metoprolol (non-adherence) & $\begin{array}{l}\text { Antiarrythmic agents, } \\
\text { Antihypertensives }\end{array}$ \\
\hline KUH & high low blood pressure & $\begin{array}{l}\text { amlodipine switched to valsartan } \\
\text { two weeks ago (due to swollen } \\
\text { ankles) }\end{array}$ & Antihypertensives \\
\hline KUH & severe dizziness & $\begin{array}{l}\text { candesartan }+ \text { lercanidipine }+ \\
\text { hydrochlorothiazide }+ \\
\text { temazepam }\end{array}$ & $\begin{array}{l}\text { Antihypertensives, Diuretics, } \\
\text { Benzodiazepines }\end{array}$ \\
\hline KUH & collapse & $\begin{array}{l}\text { furosemide }+ \text { telmisartan }+ \\
\text { bisoprolol }(+ \text { low blood pressure })\end{array}$ & Antihypertensives \\
\hline KUH & $\begin{array}{l}\text { fall, urinary tract infection, } \\
\text { hyperkalemia }\end{array}$ & $\begin{array}{l}\text { losartan (hyperkalemia) } \\
\text { oxybutynin }+ \text { amitriptyline }+ \\
\text { chlordiazepoxide }\end{array}$ & $\begin{array}{l}\text { Antihypertensives, } \\
\text { Anticholinergics }\end{array}$ \\
\hline KUH & fall & $\begin{array}{l}\text { valsartan + hydrochlorothiazide } \\
+ \text { furosemide }+ \text { spironolactone } \\
\text { (+ low blood pressure and } \\
\text { dehydration) }\end{array}$ & Antihypertensives, Diuretics \\
\hline KUH & fall & $\begin{array}{l}\text { amlodipine }+ \text { bisoprolol }+ \\
\text { ramipril }\end{array}$ & Antihypertensives \\
\hline KUH & fall & $\begin{array}{l}\text { solifenasine }+ \text { metoprolol }+ \\
\text { candesartan }(+ \text { hyponatremia })\end{array}$ & $\begin{array}{l}\text { Antihypertensives, } \\
\text { Anticholinergics }\end{array}$ \\
\hline KUH & fall & $\begin{array}{l}\text { oxazepam }+ \text { diazepam }+ \\
\text { levomepromazine }+ \text { tamsulosin }\end{array}$ & $\begin{array}{l}\text { Antipsychotics, } \\
\text { Benzodiazepines, Urologicals, } \\
\text { Alpha blockers }\end{array}$ \\
\hline KUH & fall, weakened general condition & $\begin{array}{l}\text { lisinopril + hydrochlorothiazide } \\
+ \text { metoprolol }+ \text { simvastatin }\end{array}$ & $\begin{array}{l}\text { Antihypertensives, Diuretics, } \\
\text { Statins }\end{array}$ \\
\hline KUH & weakened general condition & $\begin{array}{l}\text { furosemide (+ renal insufficiency } \\
+ \text { dose increased lately) }\end{array}$ & Diuretics \\
\hline KUH & cholecystitis & $\operatorname{Dida}^{\circledR}$ & Herbal Supplement \\
\hline KUH & arrhythmia, nausea, heartburns & digoxin (+ renal insufficiency) & Inotropic medications \\
\hline KUH & atrial fibrillation & isosorbide mononitrate & Nitrates \\
\hline KUH & $\begin{array}{l}\text { diverticulitis, constipation leg } \\
\text { muscle cramps }\end{array}$ & atorvastatin & Statins \\
\hline
\end{tabular}

ASA = acetylsalicylic acid. 
The clinical pharmacists were able to identify the patients with clinically relevant drug-related problems by using the agreed criteria. Hence, there is no urgent need for a referral for a medication review by a physician or nurse. All the reported drug-related problems were accepted by the study supervising physicians and are thus, clinically relevant. The clinical pharmacists were able to perform an effective medication review after only a short training. Earlier studies show that medication reviews reduce ED visits and an inpatient medication review conducted by pharmacists in close contact with physicians might lead to fewer admissions and lower morbidity [25, 26]. An inpatient clinical pharmacist service in the ED setting may also improve the safety of prescribing drugs and the patients' health-related quality of life [27]. After this study, HUS increased the clinical pharmacy services in its ED from a halfday to a full-day (office hours) and the additional time is now allocated to medication reconciliation and medication reviews for the patients with polypharmacy, high alert medications, renal insufficiency and/or continuing ED visits. Medication reviews have been conducted by the clinical pharmacist in the ED of KUH on a weekly basis before and after this study.

The results of medication reconciliations were similar, but results of the medication reviews showed some differences between HUS and KUH groups. These disparities between the two centres can be explained by the differences in the patient characteristics and the method of operation between the two ED units. Patients are admitted at HUS tertiary ED only by referral or are taken there by ambulance. The findings for HUS were, therefore, characteristic of a more severe setting (e.g. more severe admission diagnoses and more high-alert medications related to admissions; Table 3) and there were more drugrelated problems per patient than that found for the KUH group (Table 2). Moreover, there were also primary care patients in the secondary/primary ED of KUH whom had come directly from home with several admission diagnoses of symptoms and signs e.g. dizziness, weakened general condition and falls (Tables 3 and 4) and the patients at KUH were slightly older and used more medications (Table 1) than their HUS counterparts. Although the findings at KUH were less severe compared to HUS, they are not less important. If these drug-related problems are not resolved, the patients will burden the health care system with repeated visits and readmissions.

High-alert medications in many countries, including Finland, are not officially defined. This study provides additional information about high-alert medications of older ED patients at the admission stage. The drug-related problems identified in the medication reviews accumulated for certain specific medications, which enabled the identification of unit specific high-alert medications. High-alert medications listed in the ISMP were involved in the admission of eight patients (11\%) in HUS and six patients (8\%) in the KUH group (Table 3) [10,11]. These included antithrombotics, cytostatics, opioids and oral hypoglycaemic agents. The antithrombotics and cytostatics were also the leading causes of drug-related inadvertent deaths in HUS in 2000 and in 2012 [28]. Regarding the non-high-alert medications, antihypertensives and diuretics were commonly related to admission diagnoses in this study (Table 3). When drug-related visits to a HUS district hospital ED were studied in 2001-2002, antibiotics, cardiovascular drugs and non-steroidal anti-inflammatory drugs (NSAIDs) were the leading causes for adverse drug reactions [29].

\subsection{Study limitations}

This study focused only on Finnish, home-dwelling older ( $\geq 65$ year-old) ED patients, which might be regarded as a limitation. The aim of this study, however, was to demonstrate the need for enhancing the recording of medication history at admission of older ED patients in Finland. Patients receiving home-care were excluded, because their medication charts were considered to be under better control. According to a recent Finnish study, the majority of the home care clients had discrepancies between in-home interview data and electronic medical records, and $40 \%$ of these discrepancies were clinically important [30]. Hence, home care patients might also benefit from medication reconciliation and 
medication reviews. The differences between the findings of the medication reviews conducted in HUS and KUH can be explained by the differences in the patient details and in the respective ED unit procedures. Medication reviews were conducted in HUS and KUH by different teams, which may have affected the findings. The clinical pharmacist of KUH introduced the clinical pharmacist of HUS to the medication review procedure before the study commenced in order to harmonize the medication reviews and minimize the risk of discrepancy due to differences in procedures. The teams had several meetings during the study and the analyses of these data were made in close collaboration with the study personnel of both centres.

\section{Conclusions}

A significant number of hospital stays for older patients are drug-related. This study showed that the ED medication history taking procedure including reconciliation and review must be developed further not only in primary and secondary hospital EDs but also in tertiary hospital EDs in Finland. Trained clinical pharmacists were able to choose the patients and perform medication reviews, without disturbing or impeding the normal ED routines and thus, allowed the nurses and physicians to concentrate on the assessment and treatment of the patient. Furthermore, the drug-related problems identified with regard to medication reviews accumulated for specific medications. Medication reviews help to identify the high-alert medications at the ED admission stage and facilitate the compilation of a specific high-alert medication list relevant to the emergency admission stage. Such lists should be created in every ED setting.

\section{Supplementary material}

The Additional files are available in the electronic version of this article: http://dx.doi.org/ 10.3233/JRS-180030.

\section{Acknowledgments}

We want to thank clinical pharmacists Anu Ahonen and Väinö Vähämäki, who conducted the medication reconciliations and reviews and study physician Markku Vänttinen for supervising them at the ED in KUH. We also want to thank other ED staff in KUH and HUS for their help during the study.

\section{Authors' contributions}

LS, RO, OL-R, and JA designed the study. LS reviewed the literature. LS, AA, and VV collected the data and LS and RO conducted the analyses of the data. LS wrote the preliminary research report for the study and also prepared the manuscript for publication with the guidance of OL-R. OL-R, JA, AA, MA and LL reviewed the used methods and critically revised drafts of the manuscript. LL applied and received the Finnish governmental research funding, which enabled LS's contribution to the data collection, analyses of the data and writing of the manuscript. RO received the KUH grant, which enabled RO's contribution to the analyses of the data. All the authors read and approved the final manuscript. 


\section{Conflict of interest}

The authors declare that they have no competing interest.

\section{Ethics approval and consent to participate}

This study follows the World Medical Association's Declaration of Helsinki and was approved by the Coordinating ethics committee of HUS (36/13/03/00/14) and the KUH ethics committee (21//2014). All study participants gave written informed consent before taking part in the study. This manuscript does not contain any data on individual patient.

\section{Funding}

The study was supported by Finnish governmental research funding (study grant TYH2014224) and KUH Grant.

\section{Trial registration}

This study was prospectively registered to research registries of Helsinki University Hospital (TYH 2014224, research permit date: May 21, 2014) and Kuopio University Hospital (21//2014, research permit date: March 27, 2014).

\section{References}

[1] Tully M, Buchan I. Prescribing errors during hospital inpatient care: Factors influencing identification by pharmacists. Pharm World Sci. 2009;31:682-8.

[2] Chin MH, Wang LC, Jin L, Mulliken R, Walter J, Hayley DC Karrison TG, Nerney MP, Miller A, Friedmann PD. Appropriateness of medication selection for the older persons in an urban academic emergency department. Acad Emeg Med. 1999;6:1232-42.

[3] Caterino J, Emond J, Carmagno C. Inappropriate medication administration to the acutely ill elderly: Nationwide emergency department study, 1999 - 2000. J Am Geriatr Soc. 2004;52:1847-55.

[4] Dobrzanski S, Hammond I, Khan G, Holdsworth H. The nature of hospital prescribing errors. Br J Clin Govern. 2002;7:187-93.

[5] Institute for Healthcare Improvement. How-to Guide: Prevent Adverse Drug Events (Medication Reconciliation), 2011. http://www.ihi.org/resources/Pages/Tools/HowtoGuidePreventAdverseDrugEvents.aspx. Accessed 30 November 2017.

[6] De Winter S, Spriet I, Indevuyst C, et al. Pharmacist- versus physician-acquired medication history: A prospective study at the emergency department. Qual Saf Health Care. 2010;19:371-5. doi:10.1136/qshc.2009.035014

[7] Pham JC, Story JL, Hicks RW, Shore AD, Morlock LL, Cheung DS, et al. National Study on the frequency, types, causes and consequences of voluntary reported emergency department medications errors. J Emerg Med. 2011;40:485-92.

[8] ElDesoky E. Pharmacokinetic-pharmacodynamic crisis in the elderly. Am J Ther. 2007;14:488-98.

[9] Blix H, Viktil K, Moger T, Reikvam A. Drugs with narrow therapeutic index as indicators in the risk management of hospitalised patients. Pharm Pract. 2010;8:50-55.

[10] Institute for Safe Medication Practices (ISMP). ISMP's List of High Alert Medications in Acute Care Settings, 2014. www.ismp.org/tools/institutionalhighAlert.asp. Accessed 30 November 2017.

[11] Institute for Safe Medication Practices (ISMP). ISMP's List of High Alert Medications in Community/Ambulatory Healthcare, 2011. https://ismp.org/communityRx/tools/ambulatoryhighalert.asp. Accessed 30 November 2017.

[12] Hepler C, Strand L. Opportunities and responsibilities in pharmaceutical care. Am J Hosp Pharm. 1990;47:533-43.

[13] American Pharmacists Association, National Chain of Drug Stores Foundation: Medication Therapy Management in pharmacy practise: Core elements of an MTM service model (version 2.0). J Am Pharm. 2008;48:341-53.

[14] Bulajeva A, Labberton L, Leikola S, Pohjanoksa-Mäntylä M, Geurts MM, de Gier JJ, Airaksinen M. Medication review practices in European countries. Res Social Adm Pharm. 2014;10:731-40. 
[15] National Institute for Health and Care Excellence. Medicines optimisation: The safe and effective use of medicines to enable the best possible outcomes. NICE Guideline. Published 4 March 2015. nice.org.uk/guidance/ng5. Accessed 30 November 2017.

[16] Briggs S, Pearce R, Dilworth S, Higgins I, Hullick C, Attia J. Clinical pharmacist review: A randomised controlled trial. Emerg Med Australas. 2015;27:419-26.

[17] Nickel CH, Ruedinger JM, Messmer AS Maile S, Peng A, Bodmer M, Kressing RW, Kraehenbuehl S, Bingisser R. Drug - related emergency department visits by elderly patients presenting with non-specific complaints. Scandinavian Journal of Trauma, Resuscitation and Emergency Medicine. 2013;21:15.

[18] Leikola S, Tuomainen L, Peura S, Laurikainen A, Lyles A, Savela E, Airaksinen M. Comprehensive medications review: Development and collaborative procedure. Int J Clin Pharm. 2012;34:510-41.

[19] Dimitrow M, Mykkänen S, Leikola S, Kivelä S-L, Lyles A, Airaksinen M. Content validation of a tool for assessing risks for drug-related problems to be used by practical nurses caring for home-dwelling clients aged $\geq 65$ years: A Delphi survey. Eur J Clin Pharmacol. 2014;70:991-1002.

[20] Clyne W, Blenkinsopp A, Seal R (2008) A Guide to Medication Review. NHS, National Prescribing Centre, 2008. http://www2.cff.org.br/userfiles/52\%20-\%20CLYNE\%20W\%20A\%20guide\%20to\%20medication\% 20review\%202008.pdf. Accessed 30 November 2017.

[21] Tam VC, Knowles SR, Cornish PL, Fine N, Marchesano R, Etchells EE. Frequency, type and clinical importance of medication history errors at admission to hospital: A systematic review. CMAJ. 2005;173;510-15.

[22] Mueller SK, Sponsler KC, Kripalani S Schnipper JL. Hospital-based medication reconciliation practices: A systematic review. Arch Intern Med. 2012;172:1057-69.

[23] Hanlon J, Schmader K, Koronkowski M. Adverse drug events in high risk older outpatients. J Am Geriatr Soc. 1997;45:945-48.

[24] Beijer H, Blaey C. Hospitalisations caused by adverse drug reactions (ADR). A meta-analysis of observational studies. Pharm World Sci. 2002;24:46-54.

[25] Christensen M, Lundh A. Medication review in hospitalized patients to reduce morbidity and mortality (Review). Cochrane Database Syst Rev. 2016;2:CD008986.

[26] Gillespie U, Alassaad A, Henrohn D, Garmo H, Hammarlund-Udenaes M, Toss H, Kettis_lindblad A, Melhus H, Mörlin C. A comprehensive pharmacist intervention to reduce morbidity in patients 80 years or older: A randomized controlled trial. Arc Intern Med. 2009; 169:894-900.

[27] Bladh L, Ottosson E, Karlsson J, Klintberg L, Wallerstedt SM. Effects of a clinical pharmacist service on health-related quality of life and prescribing of drugs: A randomized controlled trial. BMJ Qual Saf. 2011;20:738-746.

[28] Lapatto-Reiniluoto O, Patinen L, Niemi M, Backman J, Neuvonen P. Drug-Related Inadvertent Deaths in a University Hospital - A Declining Trend. Basic Clin Pharmacol Toxicol. 2015;117:421-6.

[29] Juntti-Patinen L, Kuitunen T, Pere P, Neuvonen P. Drug-related visits to a district hospital emergency room. Basic Clin Pharmacol Toxicol. 2006;98:212-7.

[30] Tiihonen M, Nykänen I, Ahonen R, Hartikainen S. Discrepancies between in-home interviews and electronic medical records on regularly used drugs among home care clients. Pharmacoepidemiol and Drug Saf. 2015;25:100-5. 